\title{
Correction to: Sustainable Solutions for Urban Water Security
}

\section{Correction to:}

B. K. Mishra et al., Sustainable Solutions for Urban Water Security, Water Science and Technology Library 93, https://doi.org/10.1007/978-3-030-53110-2

The original version of the book was inadvertently published without funder information, which has now been added. The book has been updated with this change. 